Whitworth Digital Commons

Whitworth University

Health Sciences Faculty Scholarship

Health Sciences

2016

\title{
Patient-reported efficacy 6 months after a 4-week rehabilitation 1 intervention in individuals with chronic ankle instability
}

Cynthia J. Wright

Whitworth University, cwright@whitworth.edu

Shelley W. Linens

University of Oregon

Follow this and additional works at: http:// digitalcommons.whitworth.edu/healthsciencefaculty

Part of the Medicine and Health Sciences Commons

\section{Recommended Citation}

Wright CJ, Linens SW. Patient-reported efficacy 6 months after a 4-week rehabilitation intervention in individuals with chronic ankle instability. Journal of Sports Rehabilitation, 2016. In Press.

This Article is brought to you for free and open access by the Health Sciences at Whitworth University. It has been accepted for inclusion in Health Sciences Faculty Scholarship by an authorized administrator of Whitworth University. 


\section{Patient-reported efficacy 6 months after a 4-week rehabilitation}

\section{2 intervention in individuals with chronic ankle instability}

3 Wright, Cynthia J. and Linens, Shelley W.

Objective: To track the patient-reported efficacy of a 4-week intervention [wobble board (WB)

5 or resistance tubing (RT)] in decreasing symptoms of Chronic Ankle Instability (CAI) at 6 months post-intervention (6PI) as compared to immediately post-intervention (IPI). Design:

7 Randomized controlled trial. Participants: Fourteen out of 21 participants $(66.7 \%)$ responded to an electronic 6 month follow-up questionnaire (age: 19.6 \pm 0.9 years, height: $1.63 \pm 0.18 \mathrm{~m}$, weight: $70.5 \pm 16.3 \mathrm{~kg}, 2$ males, 12 female, $5 \mathrm{WB}, 9 \mathrm{RT})$. All participants met CAI criteria at enrollment, including a history of ankle sprain and recurrent episodes of giving way. Interventions: Participants completed either RT or WB protocols, both 12 sessions over 4 weeks of progressive exercise. WB sessions consisted of five 40 second sets of clockwise and counter-clockwise rotations. RT sessions consisted of 30 contractions against resistance tubing in each of 4 ankle directions. Main Outcome Measurements: Patient reported symptoms of giving-way preintervention and at 6PI, Global rating of change (GRC) frequencies at IPI and 6PI, and re-sprains at 6PI were reported descriptively. Changes in Global rating of function (GRF) and giving-way were compared using Wilcoxon tests, while GRC was compared with Fisher's exact test. at 6PI. Re-sprains occurred in $21.4 \%$ of participants. Giving-way frequency $(\mathrm{P}=0.017)$, but not GRF or GRC (P>0.05), was significantly different at IPI versus 6PI. Conclusions: Simple 4week interventions maintained some but not all improvements at 6PI. Importantly, at least

$2242.9 \%$ of participants would no longer meet the current study's CAI inclusion criteria due to a 23 reduction in giving-way. 


\section{Introduction}

Ankle sprains are one of the most common injuries associated with physical activity, with a prevalence of $42-70 \% .^{1,2}$ Developing following initial sprain in $32 \pm 9 \%$ of patients, chronic ankle instability (CAI) is characterized by sensations of giving-way of the ankle, repeated sprains and instability. ${ }^{3-6}$ The residual symptoms of CAI can limit physical activity and activities of living for years post-injury, ${ }^{3,7,8}$ and have been reported to decrease health related quality of life. ${ }^{9,10}$

Thus, treatment that improves the long-term outcomes of this pathology is very important to clinicians. Currently, there is limited data available on long-term (defined as $\geq 6$ months) maintenance of improvements seen after rehabilitation interventions for CAI. For example, of 14 controlled interventions targeted at CAI reviewed by O'Driscoll and Delahunt in $2011^{11}$, only 1 reported follow-up of 6 months or greater; ${ }^{12}$ instead most studies recorded laboratory measures (e.g. strength, force plate variables, muscle latency) immediately following the intervention. Eils and Rosenbaum ${ }^{12}$ reported a $60 \%$ reduction in frequency of ankle inversion episodes (givingway) 1 year after a 6 week multi-station proprioceptive exercise program. Recent studies are more likely to include important patient-oriented outcomes measures in addition to clinicianoriented and laboratory measures, but still largely lack long-term follow-up. ${ }^{13-22}$

While there is limited long-term data on interventions specifically targeted towards decreasing symptoms of CAI in currently symptomatic patients, a larger evidence base exists regarding interventions aimed at preventing acute lateral ankle sprains and/or the incidence of CAI post-acute ankle sprain. Specifically, prophylactic balance and coordination training (including wobble board training) in a general athletic population can decrease injury incidence, especially in those with a previous history of ankle injury. ${ }^{23}$ Additionally, balance and coordination training following an acute lateral ankle sprain reduces the risk of re-injury in the 
next $8-12$ months by $54-76 \%,{ }^{24,25}$ and prevented felt instability of the ankle in all training group participants (compared to an incidence of $25 \%$ in the control group) ${ }^{25}$ Despite its common clinical use, the efficacy of ankle joint strengthening using resistance tubing at reducing CAI or repeated sprains has not been previously reported in the literature (although it has been shown to increase strength $\left.{ }^{26}\right){ }^{27}$

In summary, while there is good evidence for the effectiveness of rehabilitation interventions to prevent initial and recurrent sprains of the ankle, there is insufficient evidence regarding the long-term effectiveness of interventions specifically targeting stability in individuals who have already developed CAI. The immediate effect of an intervention is important and helpful in understanding the mechanisms by which an intervention either is or is not effective. ${ }^{13-22}$ However, if benefits obtained through rehabilitation do not last, the utility of the intervention is limited. Although potentially costly and logistically difficult to obtain, longterm follow-up data provides essential information to clinicians about the efficacy of treatment. Thus, it was the purpose of the current research to track the patient-reported efficacy of a 4-week intervention aimed to decrease symptoms of CAI at 6 months after the completion of the intervention.

\section{Methods}

\section{Participants}

Twenty-one physically active individuals with CAI were recruited from a university undergraduate population. These individuals are a subset of a larger two-site randomized controlled trial $^{27}$; all participants from 1 clinical site were recruited for this 6 month follow-up. Inclusion criteria included a history of $\geq 1$ inversion ankle sprain which required protected weight bearing, immobilization, and/or limited activity for $\geq 24$ hours. ${ }^{28}$ The initial sprain must have 
72 occurred greater than 1 year prior to study enrollment. ${ }^{29}$ Additionally, subjects had to self-report 73 recurrent episodes of giving-way, and have a Cumberland Ankle Instability Tool (CAIT) on the 74 involved side of $\leq 25 .^{30}$ In the case of bilateral instability, the subjectively reported worse ankle 75 was considered the involved ankle.

Participants were excluded if they had a history of fracture or surgery to the involved

77 knee, lower leg or ankle, or if they participated in $<1.5$ hours of moderate-vigorous physical 78 activity per week. Participants were also excluded if they had any acute symptoms of lower 79 extremity musculoskeletal injury on the day of testing. The University Institutional Review 80 Board approved the study.

\section{Testing Procedures}

82 Participants reported to the testing facility for enrollment procedures and baseline 83 evaluation. Following informed consent, participants completed an injury history questionnaire, 84 the CAIT and a global rating of function (GRF). The injury history questionnaire collected 85 information about the initial ankle sprain, symptoms of giving way and re-sprains, and 86 rehabilitation history (see Table 1). A customized computer program (Access, Microsoft

87 Corporation, Redmond, WA) recorded and scored the CAIT and GRF. The GRF is a single-item question: "On a scale from 0-100, what would you rate your ankle use as if $0=$ no use of your

89 ankle (cannot put weight on it at all) and 100 = full use of your ankle (not limited at all)?" The

90 CAIT evaluates perceived ankle instability, has excellent test-retest reliability (intraclass

91 correlation coefficient $\left.[\mathrm{ICC}]_{2,1}=0.96\right)$, and is scored on a 30-point scale, with lower scores

92 indicating decreased stability. ${ }^{30,31}$

Next, the investigator measured and recorded participant height, weight, and ankle laxity.

94 Ankle laxity testing procedures have been previously described, ${ }^{32,33}$ but in brief, consisted of a 95 standardized anterior drawer test and talar tilt test. Both tests were graded on a scale of 1 to 5 
96 per the methods of Ryan ${ }^{33}$ then condensed into clinically-relevant categories of positive (>3) and

97 negative $(\leq 3)$. Intra-rater reliability of these methods has been reported as ICC $>0.80$ and

98 standard error of the measure $<0.25$ points. ${ }^{34}$ Participants completed baseline testing that

99 included completion of several additional patient-oriented questionnaires and clinical tests,

100 which are reported elsewhere. ${ }^{27}$ Following all baseline testing, the participant was block

101 randomized to either the resistive tubing (RT) or wobble board (WB) training group. The WB

102 protocol $^{16,27}$ has been previously reported, in brief it consisted of five repetitions of standing

103 balance on a wobble board while rotating clockwise and counterclockwise for 40 seconds each

104 repetition. The RT protocol has also been previously reported, ${ }^{26,27}$ and in brief consisted of

105 resistance tubing exercises in each of four ankle movements (dorsiflexion, plantarflexion,

106 eversion and inversion) for 3 sets of 10 repetitions. Both protocols were progressed

107 systematically as previously described. The participant received instruction for his or her

108 training group and completed the first exercise session on the enrollment day. Each participant 109 then continued to complete 3 supervised sessions each week for 4 weeks (total of 12 sessions). ${ }^{35-}$ $110 \quad 37$

Upon completion of the 4 week protocol, all baseline measures were post-tested and

112 participants completed a global rating of change (GRC) survey. The GRC asked participants to

113 rank on a 13-point scale any change in the condition of their ankle. Participants selecting any of

114 the nine responses ranging from "a very great deal worse" to "somewhat better" were

115 dichotomously categorized as not improved, whereas the four responses ranging from

116 "moderately better" to "a very great deal better" were categorized as improved. Participants did

117 not formally continue ankle exercises after the $12^{\text {th }}$ session. It is possible (but unlikely)

118 participants continued these exercises on their own as they were not given the rehabilitation

119 equipment nor was it easily accessible to them. Then at 6 months post-completion, a single 
120

121

122

123

124

125

126

127

128

129

130

131

132

133

134

135

136

137

138

139

140

141

142

email was sent to all participants requesting that they complete a simple 7-question online survey. This survey recorded ankle sprain incidence, the presence and frequency of episodes of giving-way, GRC and GRF at 6 months post-intervention.

\section{Data Analysis}

Patient-reported symptoms of giving-way pre-intervention and at 6 month postintervention, and GRC frequencies immediately post-intervention and at 6 months postintervention are presented descriptively (Table 2). A Wilcoxon signed rank test was used to test differences between (1) GRF immediately post-intervention and at 6 months post-intervention, and (2) giving-way frequency pre-intervention and at 6 months post-intervention. GRC was compared immediately post-intervention to 6 months post-intervention using Fisher's exact test. Data is presented separately by treatment group and combined across treatment groups; however, due to small sample size statistical analysis was only performed on combined data. To assess for bias in follow-up survey responders versus those lost to follow-up, characteristics of both groups were also compared: continuous variables (such as height, age, etc.) were compared using paired t-tests, all categorical variables (such as gender, laxity, etc.) were compared using Fisher's exact test except for initial injury severity which was compared using a chi-squared test. All alpha were set a priori at $\alpha=0.05$.

\section{Results}

Fourteen out of 21 participants $(66.7 \%)$ responded to an electronic 6 month follow-up questionnaire. Respondent demographics and injury characteristics are shown in Table 1. Four recurrent ankle sprains were reported in 3 separate participants; all other patient reported outcomes are shown in Table 2 . GRF did not change significantly between measurement 
143 immediately post-intervention and 6 months later $(\mathrm{Z}=-1.185, \mathrm{P}=0.236)$. However, episodes of 144 giving-way per month were significantly decreased at 6 months post-intervention compared to 145 pre-intervention $(\mathrm{Z}=02.121, \mathrm{P}=0.034)$. The frequency of participants whose GRC indicated they

146 were improved was not different between immediately post-intervention and 6 months later

147 (Fisher's exact test $\mathrm{P}=0.559$ ). Individuals who were lost to 6 month follow-up were not

148 significantly different than survey participants in any variable except whether or not they had 149 previously completed some type of ankle rehabilitation (Table 3). Specifically, individuals lost 150 to follow-up reported a prior history of ankle rehabilitation at a greater frequency than follow-up 151 survey participants.

\section{Discussion}

Twenty-one ankle rehabilitation participants were invited to complete a 6 month followup survey, and $14(66.7 \%)$ responded. In these participants, the simple 4-week WB and RT interventions used in the current study maintained improvements in GRF and GRC at 6 months

157 post-intervention, decreased total number of participants reporting episodes of giving-way to 158 $43 \%$, as well as decreased the monthly frequency of these episodes of giving-way. However, re-

159 current ankle sprains were still experienced by 3 (21.4\%) participants.

\section{Effect on symptoms of giving-way}

To our knowledge, this is the first time that long-term follow-up has been completed on a

162 simple single-exercise protocol like our WB and RT. The limited existing literature on long-

163 term results for individuals with CAI only provides evidence regarding a comprehensive multi-

164 exercise program. ${ }^{12}$ Eils and Rosenbaum ${ }^{12}$ reported a $60 \%$ reduction in episodes of giving-way 1

165 year post-intervention, which is similar to the magnitude of reduction found in the current study 
(61\%). Additionally, previous research using the same WB and RT protocol documented improvements in patient- and clinician-oriented outcomes immediately post-intervention. ${ }^{27}$ Interestingly the magnitude of those differences was similar to that reported in previous multiexercise interventions. ${ }^{27}$ This indicates that immediately post-intervention, the RT and WB protocols are at least as effective as more complex interventions, while potentially saving time and resources. The current research adds additional evidence that a single-exercise protocol can also be effective at reducing symptoms of CAI for least 6 months post-intervention.

Our CAI inclusion criteria largely aligned with the International Ankle Consortium (IAC) position statement (which was published after data collection began). ${ }^{29}$ This statement recommends inclusion criteria for CAI include at a minimum (a) a history of 1 significant ankle sprain, and (b) a history of the injured ankle giving-way and/or recurrent sprain and/or feelings of instability. ${ }^{29}$ More specifically, participants should report at least 2 episodes of giving-way in the past 6 months and self-reported instability would preferably be confirmed with questionnaires such as the CAIT. ${ }^{29}$ While the first criterion (history of ankle sprain) is nonmodifiable, the second criterion can change over time. Perhaps the most significant finding of the current study was that $42.9 \%$ of participants would no longer meet CAI inclusion criteria due to lack of giving-way at 6 month follow-up. Unfortunately, we were not able to re-administer the CAIT at 6 month follow-up, thus, it is unknown whether even more participants would have been excluded for exceeding the CAIT cutoff score of $\leq 25$. Even without this data, it is important that almost half of participants had improved sufficiently to no longer be classified as CAI according to IAC criteria. $^{29}$

\section{Effect on Global Rating of Change}

Although not significantly different, the number of participants who self-reported that the condition of their ankle was improved was lower at 6 months than directly after the intervention 
190 (71.4\% improved immediately post-intervention, 50\% improved at 6 months). Thus, by this

191

192

193

194

195

196

197

198

199

200

201

202

203

204

205

206

207

208

measure the current protocol demonstrated long term success for approximately half of participants, but failed the other half. Obviously, the ideal intervention would achieve both short-term results and maintain long-term success in $100 \%$ of patients. While achieving $100 \%$ success may not be realistic, improving on the current results is a realistic goal. Future work should test the long-term efficacy of other rehabilitation protocols or interventions, in an attempt to identify more effective techniques. One specific recommendation would be to test the efficacy of an ongoing maintenance plan following a formal intervention. The individuals in the current study were not instructed (nor provided the resources) to continue rehabilitation after the initial 4 week intervention, making it unlikely that any continued with their rehabilitation program. Based on this study design, it is unknown whether an ongoing maintenance exercise plan would have affected the 6 month follow-up data. However, common clinical reasoning is that some form of maintenance exercise is essential to maintain results. Additionally, it is interesting to note that based on reported GRC immediately and 6-months post-intervention, there may be a difference in maintenance needs for WB versus RT. Future research into the best dose and exercise type for maintenance would aid clinicians in developing evidence based exercise prescription. Additionally, future work should identify which modifiable factors were most predictive of self-reported long-term improvement as measured by the GRC, and then attempt to modify those factors to improve treatment efficacy.

\section{Limitations and Considerations for Future Research}

The chief limitation of this study is the small sample size. Unfortunately, due to an IRB limitation at one (of two) clinical sites of the original larger study, we were only able to invite the 21 participants from one clinical site to participate in the follow-up survey. Due to the small sample size we were not able to statistically compare the efficacy of our two interventions (WB 
214 or RT). As our sample was recruited exclusively from a small residential university, our 6 month 215 response rate was likely affected when the 6 month follow-up fell over summer break or post216 graduation. Although the response rate of $67 \%$ was lower than desired, comparison of the 217 characteristics of the individuals lost to follow-up versus those who responded to our survey 218 provided evidence of a representative sample (Table 3). Of sixteen characteristics (including 219 injury severity, giving-way frequency, laxity, etc.) only the frequency of a reported history of 220 prior rehabilitation differed between survey responders and non-responders. It is unclear the 221 meaning (if any) of this singular difference. Future work should document the long-term 222 efficacy of these interventions in a larger sample so that statistical comparisons can be made and 223 conclusions drawn concerning the most effective technique.

224 We defined long-term follow-up as 6 months post-intervention as this seems to be the 225 minimum long-term follow-up period in related literature. Ideally, we would have tracked 226 subjects for a longer time period, however, practical considerations limited follow-up to 6 227 months. Future research should track efficacy at 1 year and further time points. Additionally, if 228 a wash-out effect over time is noted, it would be clinically advantageous to investigate the 229 minimum frequency of exercise required to maintain rehabilitation benefits. For example, would 2301 rehabilitation session a week be sufficient to maintain improvements?

Our follow-up survey asked participants to self-report the incidence of recurrent sprain

232 and frequency of giving-way. Self-reported data is potentially subject to recall bias or error.

233 Specifically, participants could have erred in their definition of what constituted a re-sprain.

234 However, the questionnaire did attempt to address this issue by including the clarification " $\mathrm{A}$ 235 sprain is an acute ankle injury, generally resulting in pain, swelling and decreased function". 236 Future research could require all subsequent sprains to be documented by a healthcare provider, 
237 however, given the fact that many people do not seek treatment for ankle sprains ${ }^{38}$ this may 238 underestimate the true frequency of recurrent injury.

239

240 Conclusions

241 A simple 4-week intervention aimed at reducing the symptoms associated with CAI

242 maintained some but not all improvements at 6 months post-intervention. Importantly, $42.9 \%$ of

243 participants no longer experienced giving-way, a hallmark of CAI. Results were achieved using

244 a single-exercise protocol (WB or RT) that involved minimal time and resources, making it

245 easily accessible to patients and clinicians. 
246

247

\section{References}

1. Larsen E, Hensen PK, Jensen PR. Long-term outcome of knee and ankle injuries in elite football. Scand J Med Sci Sports 1999;9(5):285-9.

2. Smith RW, Reischl SF. Treatment of ankle sprains in young athletes. Am J Sports Med 1986;14(6):465-71.

3. Braun BL. Effects of ankle sprain in a general clinic population 6 to 18 months after medical evaluation. Arch Fam Med 1999;8(2):143-8.

4. Gerber JP, Williams GN, Scoville CR, Arciero RA, Taylor DC. Persistent disability associated with ankle sprains: A prospective examination of an athletic population. Foot Ankle Int 1998;19(10):653-60.

5. Verhagen RA, de Keizer G, van Dijk CN. Long-term follow-up of inversion trauma of the ankle. Arch Orthop Trauma Surg 1995;114(2):92-6.

6. Yeung MS, Chan KM, So CH, Yuan WY. An epidemiolgical survey on ankle sprain. Br J Sports Med 1994;28(2):112-6.

7. Konradsen L, Bech L, Ehrenbjerg M, Nickelsen T. Seven years follow-up after ankle inversion trauma. Scand J Med Sci Sports 2002;12(3):129-35.

8. Hubbard-Turner T, Turner M. Physical activity levels in college students with chronic ankle instability. J Athl Train 2015;50(7):742-7.

9. Anandacoomarasamy A, Barnsley L. Long term outcomes of inversion ankle injuries. Br J Sports Med 2005;39(3):14-7.

10. Arnold BL, Wright CJ, Ross SE. Functional ankle instability and health-related quality of life. J Athl Train 2011;46(6):634-41.

11. O'Driscoll J, Delahunt E. Neuromuscular training to enhance sensorimotor and funcitonal deficits in subjects with chronic ankle instability: A systematic review and best evidence synthesis. Sports Med Arthrosc Rehabil Ther Technol 2011;3(19):1-20.

12. Eils E, Rosenbaum D. A multi-station proprioceptive exercise program in patients with ankle instability. Med Sci Sports Exerc 2001 Dec;33(12):1991-8.

13. Cruz-Diaz D, Lomas-Vega R, Osuna-Pérez MC, Contreras FH, Martínez-Amat A. Effects of 6 weeks of balance training on chronic ankle instability in athletes: A randomized controlled trial. Int J Sports Med 2015;36(9):754-60.

14. De Ridder R, Willems TM, Vanrenterghem J, Roosen P. Effect of a home-based balance training protocol on dynamic postural control in subjects with chronic ankle instability. Int $\mathrm{J}$ Sports Med 2015;36(7):596-602. 
15. Kim KJ, Kim YE, Jun HJ, Lee JS, Ji SH, Ji SG, Seo TH, Kim YO. Which treatment is more effective for functional ankle instability: Strengthening or combined muscle strengthening and proprioceptive exercises? J Phys Ther Sci 2014;26(3):385-8.

16. Linens SW, Ross SE, Arnold BL. Wobble board rehabilitation for improving balance in ankles with chronic ankle instability. Clin J Sports Med 2015;Epub Ahead of Print.

17. Schaefer JL, Sandrey MA. Effects of a 4-week dynamic-balance-training program supplemented with graston instrument-assisted soft-tissue mobilization for chronic ankle instability. J Sport Rehabil 2012;21(4):313-26.

18. Smith BI, Docherty CL, Simon J, Klossner J, Schrader J. Ankle strength and force sense after a progressive, 6-week strength-training program in people with functional ankle instability. J Athl Train 2012;47(3):282-8.

19. Mettler A, Chinn L, Saliba SA, McKeon PO, Hertel J. Balance training and center-ofpressure location in participants with chronic ankle instability. J Athl Train 2015;50(4):3439.

20. Hall EA, Docherty CL, Simon J, Kingma JJ, Klossner JC. Strength-training protocols to improve deficits in participants with chronic ankle instability: A randomized controlled trial. J Athl Train 2015;50(1):36-44.

21. Han K, Ricard MD. Effects of 4 weeks of elastic-resistance training on ankle-evertor strength and latency. J Sport Rehab 2011;20(2):157-73.

22. Han K, Ricard MD, Fellingham GW. Effects of a 4-week exercise program on balance using elastic tubing as a perturbation force for individuals with a history of ankle sprains. J Orthop Sports Phys Ther 2009;39(4):246-55.

23. McKeon PO, Hertel J. Systematic review of postural control and lateral ankle instability, part II: Is balance training clinically effective? J Athl Train 2008;43(3):305-15.

24. Holme E, Magnusson SP, Becher K, Bieler T, Aagaard P, Kjaer M. The effect of supervised rehabilitation on strength, postural sway, position sense and re-injury risk after acute ankle ligament sprain. Scand J Med Sci Sports 1999;9(2):104-9.

25. Wester JU, Jespersen SM, Nielsen KD, Neumann L. Wobble board training after partial sprains of the lateral ligaments of the ankle: A prospective randomized study. J Orthop Sports Phys Ther 1996;23(5):332-6.

26. Kaminski TW, Buckley BD, Powers ME, Hubbard TJ, Ortiz C. Effect of strength and proprioception training on eversion to inversion strength ratios in subjects with unilateral functional ankle instability. Br J Sports Med 2003;37(5):410-5.

27. Wright CJ, Linens SW, Cain MS. A randomized controlled trial comparing rehabilitation efficacy in chronic ankle instability. J Sport Rehabil In Press. 
28. Docherty CL, Arnold BL. Force sense deficits in functionally unstable ankles. J Orthop Res 2008;26(11):1489-93.

29. Gribble PA, Delahunt E, Bleakley C, Caulfield B, Docherty CL, Fourchet F, Fong D, Hertel J, Hiller C, Kaminski TW, et al. Selection criteria for patients with chronic ankle instability in controlled research: A position statement of the international ankle consortium. J Athl Train 2014;49(1):121-7.

30. Wright CJ, Arnold BL, Ross SE, Linens SW. Recalibration and validation of the cumberland ankle instability tool cutoff score for individuals with chronic ankle instability. Arch Phys Med Rehabil 2014;95(10):1853-9.

31. Hiller CE, Refshauge KM, Bundy AC, Herbert RD, Kilbreath SL. The cumberland ankle instability tool: A report of validity and reliability testing. Arch Phys Med Rehabil 2006;87(9):1235-41.

32. Wright CJ, Arnold BL, Ross SE, Ketchum JM, Ericksen JJ, Pidcoe PE. Clinical exam results differ among individuals with functional ankle instability and ankle sprain copers. J Athl Train 2012; In Press.

33. Ryan L. Mechanical stability, muscle strength, and proprioception in the functionally unstable ankle. Aust J Physiother 1994;40(1):41-7.

34. Brown C, Padua D, Marshall SW, Guskiewicz K. Individuals with mechanical ankle instability exhibit different motion patterns than those with functional ankle instability and ankle sprain copers. Clin Biomech 2008;23(6):822-31.

35. Clark VM, Burden AM. A 4-week wobble board exercise programme improved muscle onset latency and perceived stability in individuals with a functionally unstable ankle. Phys Ther Sport 2005;6(4):181-7.

36. Hale SA, Hertel J, Olmsted-Kramer LC. The effect of a 4-week comprehensive rehabilitation program on postural control and lower extremity function in individuals with chronic ankle instability. J Orthop Sports Phys Ther 2007;37(6):303-11.

37. Rozzi SL, Lephart SM, Sterner R, Kuligowski L. Balance training for persons with functionally unstable ankles. J Orthop Sports Phys Ther 1999;29(8):478-86.

38. Hiller CE, Nightingale EJ, Raymond J, Kilbreath SL, Burns J, Black DA, Refshauge KM. Prevalence and impact of chronic musculoskeletal ankle disorders in the community. Arch Phys Med Rehabil 2012;93(10):1801-7. 
Accepted author manuscript version reprinted, by permission, from Journal of Sport Rehabilitation, 2016 (in press)

CHuman Kinetics, Inc.

Table 1. Participant Demographics and Injury Characteristics

\begin{tabular}{|c|c|c|c|}
\hline Descriptor & $\begin{array}{c}\text { Wobble Board } \\
(n=5)\end{array}$ & $\begin{array}{c}\text { Resistance Tubing } \\
(n=9)\end{array}$ & $\begin{array}{c}\text { Combined } \\
(n=14)\end{array}$ \\
\hline Age, y & $19.40 \pm 0.55$ & $19.67 \pm 1.12$ & $19.57 \pm 0.94$ \\
\hline Height, m & $1.61 \pm 0.27$ & $1.64 \pm 10.93$ & $1.63 \pm 0.18$ \\
\hline Weight, kg & $77.04 \pm 19.81$ & $66.81 \pm 13.83$ & $70.48 \pm 16.26$ \\
\hline Time since initial sprain, $y$ & $5.80 \pm 3.96$ & $6.11 \pm 3.98$ & $6.00 \pm 3.82$ \\
\hline Limited weight bearing, $d$ & $18.25 \pm 27.90$ & $13.83 \pm 14.66$ & $15.60 \pm 19.60$ \\
\hline Lifetime number of re-sprains & $1.80 \pm 2.05$ & $1.67 \pm 1.50$ & $1.71 \pm 1.64$ \\
\hline Episodes of giving-way, month & $4.20 \pm 4.49$ & $9.01 \pm 19.30$ & $7.29 \pm 15.53$ \\
\hline Gender & $\begin{array}{r}2(40 \%) \text { male } \\
3(60 \%) \text { female }\end{array}$ & $\begin{array}{r}0(0 \%) \text { male } \\
9(100 \%) \text { female }\end{array}$ & $\begin{array}{r}2(14 \%) \text { male } \\
12(86 \%) \text { female }\end{array}$ \\
\hline $\begin{array}{l}\text { Initial ankle sprain evaluated by a } \\
\text { medical professional? }\end{array}$ & $\begin{array}{r}4(80 \%) \text { Yes } \\
1(20 \%) \text { No }\end{array}$ & $\begin{array}{r}6(67 \%) \text { Yes } \\
3(33 \%) \text { No }\end{array}$ & $\begin{array}{r}10(71 \%) \text { Yes } \\
4(29 \%) \text { No }\end{array}$ \\
\hline Severity of initial ankle sprain & $\begin{array}{r}1(20 \%) \text { Mild } \\
2(20 \%) \text { Moderate } \\
1(20 \%) \text { Severe } \\
1(20 \%) \text { Unknown }\end{array}$ & $\begin{array}{r}1(11 \%) \text { Mild } \\
3(33 \%) \text { Moderate } \\
2(22 \%) \text { Severe } \\
3(33 \%) \text { Unknown }\end{array}$ & $\begin{array}{r}2(14 \%) \text { Mild } \\
5(36 \%) \text { Moderate } \\
3(21 \%) \text { Severe } \\
4(29 \%) \text { Unknown }\end{array}$ \\
\hline Rehabilitation performed? & $\begin{array}{r}1(20 \%) \text { Yes } \\
4(80 \%) \text { No }\end{array}$ & $\begin{array}{r}1(11 \%) \text { Yes } \\
8(89 \%) \text { No }\end{array}$ & $\begin{array}{l}2(14 \%) \text { Yes } \\
12(86 \%) \text { No }\end{array}$ \\
\hline Rehabilitation supervised by therapist? & $\begin{array}{r}1(100 \%) \text { Yes } \\
0(0 \%) \text { No }\end{array}$ & $\begin{array}{r}1(100 \%) \text { Yes } \\
0(0 \%) \text { No }\end{array}$ & $\begin{array}{r}2(100 \%) \text { Yes } \\
0(0 \%) \text { No }\end{array}$ \\
\hline Anterior drawer laxity & $\begin{array}{l}2(40 \%) \text { positive } \\
3(60 \%) \text { negative }\end{array}$ & $\begin{array}{r}6(67 \%) \text { positive } \\
3(33 \%) \text { negative }\end{array}$ & $\begin{array}{l}8(57 \%) \text { positive } \\
6(43 \%) \text { negative }\end{array}$ \\
\hline Talar tilt laxity & $\begin{array}{l}2(40 \%) \text { positive } \\
3(60 \%) \text { negative }\end{array}$ & $\begin{array}{c}4(44 \%) \text { positive } \\
5(56 \%) \text { negative }\end{array}$ & $\begin{array}{l}6(43 \%) \text { positive } \\
8(57 \%) \text { negative }\end{array}$ \\
\hline
\end{tabular}

Values are presented as either mean \pm standard deviation or $\mathrm{n}$ (percent). 
Table 2. Participant reported outcomes at 6 months post-intervention

\begin{tabular}{|c|c|c|c|}
\hline Outcome & $\begin{array}{l}\text { Wobble Board } \\
(n=5)\end{array}$ & $\begin{array}{l}\text { Resistance Tubing } \\
(n=9)\end{array}$ & $\begin{array}{c}\text { Combined } \\
(n=14)\end{array}$ \\
\hline \multicolumn{4}{|l|}{ Episodes of giving way, yes or no? } \\
\hline Pre-intervention & $\begin{array}{c}5(100 \%) \text { Yes } \\
0(0 \%) \text { No }\end{array}$ & $\begin{array}{c}9(100 \%) \text { Yes } \\
0(0 \%) \text { No }\end{array}$ & $\begin{array}{c}14(100 \%) \text { Yes } \\
0(0 \%) \text { No }\end{array}$ \\
\hline 6 mo. Post-intervention & $\begin{array}{l}1(20 \%) \text { Yes } \\
4(80 \%) \text { No }\end{array}$ & $\begin{array}{l}7(78 \%) \text { Yes } \\
2(22 \%) \text { No }\end{array}$ & $\begin{array}{l}8(57 \%) \text { Yes } \\
6(43 \%) \text { No }\end{array}$ \\
\hline \multicolumn{4}{|l|}{ Episodes of giving way per month } \\
\hline Pre-intervention & $4.20 \pm 4.50$ & $9.02 \pm 19.30$ & $7.29 \pm 15.53^{a}$ \\
\hline 6 mo. Post-intervention & $6.00 \pm 13.42$ & $1.09 \pm 1.26$ & $2.84 \pm 7.89^{a}$ \\
\hline \multicolumn{4}{|l|}{ Global rating of change } \\
\hline Immediately post-intervention & $\begin{array}{l}5(100 \%) \text { improved } \\
0(0 \%) \text { not improved }\end{array}$ & $\begin{array}{c}5(56 \%) \text { improved } \\
4(44 \%) \text { not improved }\end{array}$ & $\begin{array}{c}10(71 \%) \text { improved } \\
4(29 \%) \text { not improved }\end{array}$ \\
\hline 6 mo. Post-intervention & $\begin{array}{c}3(60 \%) \text { improved } \\
2(40 \%) \text { not improved }\end{array}$ & $\begin{array}{c}4(44 \%) \text { improved } \\
5(56 \%) \text { not improved }\end{array}$ & $\begin{array}{c}7(50 \%) \text { improved } \\
7(50 \%) \text { not improved }\end{array}$ \\
\hline
\end{tabular}

Global rating of function

Immediately post-intervention

6 mo. Post-intervention

$95.50 \pm 2.52$

$89.75 \pm 6.90$

$91.67 \pm 6.33$

Re-sprain incidence

$90.00 \pm 16.96$

$90.89 \pm 11.21$

$90.57 \pm 12.89$

6 mo. Post-intervention

$1(20 \%)$

$2(22 \%)$

$3(21 \%)$

Numbers are presented as mean \pm standard deviation, or $\mathrm{n}$ (percent).

a Significant difference between pre-intervention and 6 months post-intervention

${ }^{\mathrm{b}}$ Total $\mathrm{N}=12$ due to missing data for 2 subjects ( 1 wobble board, 1 resistance tubing) 
Table 3. Characteristics of Survey Responders versus Non-responders

\begin{tabular}{|c|c|c|c|}
\hline Descriptor & Responders $(n=14)$ & Non-responders $(n=7)$ & P-value \\
\hline Age, y & $19.57 \pm 0.94$ & $19.86 \pm 1.22$ & 0.557 \\
\hline Height, m & $1.63 \pm 0.18$ & $1.70 \pm 0.08$ & 0.328 \\
\hline Weight, kg & $70.48 \pm 16.26$ & $71.07 \pm 10.05$ & 0.930 \\
\hline Time since initial sprain, y & $6.00 \pm 3.82$ & $7.00 \pm 3.46$ & 0.589 \\
\hline Limited weight bearing, $d$ & $15.60 \pm 19.60$ & $7.14 \pm 5.15$ & 0.286 \\
\hline Lifetime number of re-sprains & $1.71 \pm 1.64$ & $2.00 \pm 1.63$ & 0.710 \\
\hline Episodes of giving-way, month & $7.29 \pm 15.53$ & $2.67 \pm 2.73$ & 0.484 \\
\hline $\begin{array}{l}\text { Global rating of function, immediately } \\
\text { post-intervention }\end{array}$ & $91.67 \pm 6.33$ & $90.71 \pm 5.12$ & 0.740 \\
\hline $\begin{array}{l}\text { Global rating of change, immediately } \\
\text { post-intervention }\end{array}$ & $\begin{array}{r}10(71 \%) \text { improved } \\
4(29 \%) \text { not improved }\end{array}$ & $\begin{array}{r}5(71 \%) \text { improved } \\
2(29 \%) \text { not improved }\end{array}$ & 1.000 \\
\hline Gender & $\begin{array}{r}2(14 \%) \text { male } \\
12(86 \%) \text { female }\end{array}$ & $\begin{array}{r}2(29 \%) \text { male } \\
5(71 \%) \text { female }\end{array}$ & 0.574 \\
\hline $\begin{array}{l}\text { Initial ankle sprain evaluated by a } \\
\text { medical professional? }\end{array}$ & $\begin{array}{r}10(71 \%) \text { Yes } \\
4(29 \%) \text { No }\end{array}$ & $\begin{array}{r}6(86 \%) \text { Yes } \\
1(14 \%) \text { No }\end{array}$ & 0.624 \\
\hline Severity of initial ankle sprain & $\begin{array}{r}2(14 \%) \text { Mild } \\
5(36 \%) \text { Moderate } \\
3(21 \%) \text { Severe } \\
4(29 \%) \text { Unknown }\end{array}$ & $\begin{array}{r}1(14 \%) \text { Mild } \\
5(71 \%) \text { Moderate } \\
0(0 \%) \text { Severe } \\
1(14 \%) \text { Unknown }\end{array}$ & 0.369 \\
\hline Rehabilitation performed? & $\begin{array}{l}2(14 \%) \text { Yes } \\
12(86 \%) \text { No }\end{array}$ & $\begin{array}{l}5(71 \%) \text { Yes } \\
2(29 \%) \text { No }\end{array}$ & $0.017^{a}$ \\
\hline Rehabilitation supervised by therapist? & $\begin{array}{r}2(100 \%) \text { Yes } \\
0(0 \%) \text { No }\end{array}$ & $\begin{array}{l}4(57 \%) \text { Yes } \\
3(43 \%) \text { No }\end{array}$ & 0.120 \\
\hline Anterior drawer laxity & $\begin{array}{l}8(57 \%) \text { positive } \\
6(43 \%) \text { negative }\end{array}$ & $\begin{array}{l}2(29 \%) \text { positive } \\
5(71 \%) \text { negative }\end{array}$ & 0.361 \\
\hline Talar tilt laxity & $\begin{array}{l}6(43 \%) \text { positive } \\
8(57 \%) \text { negative }\end{array}$ & $\begin{array}{l}6(86 \%) \text { positive } \\
1(14 \%) \text { negative }\end{array}$ & 0.159 \\
\hline
\end{tabular}

Values are presented as either mean \pm standard deviation or $n$ (percent).

${ }^{a}$ Significant difference between groups using Fisher's exact test 